1 Morphology and Blood Metabolites Reflect Recent Spatial Differences Among Lake Winnipeg

2 Walleye, Sander vitreus

3 Matt J. Thorstensen* ${ }^{1}$, Lilian M. Wiens ${ }^{1}$, Jennifer D. Jeffrey ${ }^{1}$, Geoffrey M. Klein ${ }^{2}$, Ken M.

4 Jeffries $^{1}$, Jason R. Treberg ${ }^{1}$

$5 \quad{ }^{1}$ Department of Biological Sciences, University of Manitoba, 50 Sifton Road, Winnipeg, MB

6 R3T 2M5, Canada

$7 \quad{ }^{2}$ Manitoba Conservation and Water Stewardship, Wildlife and Fisheries Branch, 200 Salteaux

8 Crescent, Winnipeg, MB R3J 3W3, Canada

10 Abstract

11 The invasive rainbow smelt (Osmerus mordax) was an abundant food source for Lake Winnipeg

12 walleye (Sander vitreus), especially in the north basin of the lake, until the smelt's collapse in

13 approximately 2013 . We quantified changing length-at-age ( $\approx$ growth rates) and relative mass $(\approx$

14 body condition) in Lake Winnipeg walleye caught for a gillnet index data set. Here, walleye

15 showed smaller length-at-age, particularly in the north basin with young fish, over time. This

16 approach to assessing growth suggests a constraint in the north basin fish, possibly a nutritional

17 limitation between 2017 and 2018, that was not present in the south. We then analyzed a

18 separate group of walleye ( $\geq 452 \mathrm{~mm}$ in fork length) sampled in 2017 as part of a large-scale

19 tracking study, which had a similar slope in length-mass relationship to large walleye caught in

20 that year for the gillnet index data. A panel of metabolites associated with amino acid

21 metabolism and protein turnover was compared in whole blood. These metabolites revealed

22 elevated essential amino acids and suggest protein degradation may be elevated in north basin

23 walleye. Therefore, based on both growth estimates and metabolites associated with protein

24 balance, we suggest there were spatially distinct separations affecting Lake Winnipeg walleye

25 with decreased nutritional status of walleye in the north basin of Lake Winnipeg being of

26 particular concern.

\title{
28 Key Words
}

29 length-mass relationship, growth rate, endogenous protein breakdown, amino acids, freshwater 30 fishery 


\section{Introduction}

Walleye (Sander vitreus) are the largest component of the Lake Winnipeg fishery in

34 Manitoba, the second-largest freshwater fishery in Canada (Fisheries and Oceans Canada, 2018).

35 Sustainable management of these walleye is, therefore, of enormous importance to commercial

36 fishing, recreational angling, and the Lake Winnipeg ecosystem. However, annual commercial

37 yield from the Lake Winnipeg walleye fishery has been above maximum sustainable yield since

38 2002, while commercial harvests have also declined between 2014 and 2018 (Manitoba

39 Sustainable Development, 2018). Relatively recent observations of dwarf walleye, primarily in

40 the south basin, suggest a selective pressure against large individuals - a selective force possibly

41 induced by fisheries (Moles et al., 2010; Sheppard et al., 2018). Taken together, these separate

42 pieces of evidence indicate that the important Lake Winnipeg walleye fishery is faced with

43 several issues that may affect its sustainability and suggest that this fishery may need

44 conservation attention.

45 To address conservation issues such as those that the Lake Winnipeg walleye may face,

46 resource managers require many pieces of information to forecast how actions affect the

47 probability of distinct alternative futures (Gattuso et al., 2015; Dudgeon et al., 2006).

48 Simultaneous exposure to multiple stressors, such as eutrophication and invasive species, may

49 lead to cumulative detrimental impacts on a fishery (Schindler et al., 2001). One key alteration to

50 the Lake Winnipeg ecosystem was the introduction and subsequent crash of non-native rainbow

51 smelt (Osmerus mordax). The rainbow smelt were first been observed in Lake Winnipeg in late

521990 (Franzin et al., 1994), and were later found in the stomachs of $82.9 \%$ of walleye caught in

53 the north basin, but only $9.3 \%$ of walleye caught in the south basin (in 2010 and 2011, see

54 Sheppard et al., 2015). At present however, rainbow smelt have almost disappeared from Lake

55 Winnipeg, and their disappearance coincides with walleye body condition (a measure of mass

56 relative to length, or 'fatness' of the fish) declines across the lake (Caskenette et al., submitted in

57 this issue; Enders et al., submitted in this issue; Manitoba Government, 2018). As walleye body

58 condition decreases over time, implicating a reduction in available nutritional resources such as

59 the rainbow smelt, while fishing effort remains constant or rises, the recent declines in Lake

60 Winnipeg walleye abundance may be exacerbated (Manitoba Sustainable Development, 2018). 
61 Therefore, understanding how changing food availability may be affecting Lake Winnipeg

62 walleye is a fundamental issue in the system and a useful piece of information for resource

63 management.

64 However, beyond gross morphological measurements like body condition, there are few 65 available tools for evaluating the nutritional status of wild fishes outside of destructive sampling 66 and proximate composition analysis. The current study was undertaken, taking advantage of the 67 patterns of declining fish condition, to determine if there may be basin-level differences in the 68 nutritional status of walleye in Lake Winnipeg by examining body condition and growth rates 69 over time. Basin-level differences seemed most likely because the lake is characterized by two

70 large basins separated by a narrow channel (Figure 1). Our second goal was to identify potential 71 biomarkers from non-lethal sampling to test for differential nutritional status or energetic 72 demands in walleye from the different regions of the lake. With refinement and validation, such

73 biomarkers could provide managers with tools that may be able to rapidly inform on

74 physiologically relevant thresholds of nutritional constraints that would be useful in risk 75 assessments (Connon et al., 2018).

Nutritional biomarker strategy

We focused our study on protein metabolism because bulk protein growth is, with certain caveats, analogous to individual fish growth (see Carter and Houlihan, 2001 for review). Protein

80 growth is a function of the balance between the rate of synthesis of new proteins from free amino 81 acids and the rate of protein degradation, which releases free amino acids (Figure 2). Therefore,

82 if an animal is synthesizing more protein than the rate of protein breakdown, there is net growth.

83 Protein synthesis and degradation are both tightly regulated physiological processes, and as such

84 the balance between both processes are intimately linked to growth and energy balance. We

85 sought a biomarker strategy that could differentiate between amino acid breakdown for oxidation 86 as an energy source (as opposed to re-using amino acids for protein synthesis), and the extent of 87 endogenous protein breakdown in walleye across Lake Winnipeg (Figure 1). 
90 mobilized as a fuel after lipid and carbohydrate reserves are depleted (Black and Love 1986;

91 Collins and Anderson 1995). Essential, or non-dispensable, amino acids may be useful for

92 insight into amino acid oxidation in wild fish because the animal must get them through its diet,

93 and cannot rely solely on its own metabolic processes for their supply. If dietary essential amino

94 acid intake is insufficient, the fish cannot grow or may even fail to maintain body mass. For this

95 reason, increased breakdown of essential amino acids would coincide with either excess intake

96 from the diet or a need to catabolize body protein to make up for an energetic deficiency. Amino

97 acid breakdown can be implicated by the presence of metabolites that result from their

98 breakdown, and essential amino acids (specifically methionine, tryptophan, and lysine in the

99 current study) are of particular use in this context because their presence represents only food

100 intake or protein breakdown. Assuming conserved pathways of amino acid breakdown across

101 animals, methionine breakdown results in the formation of dimethyl sulfone (Engelke et al.,

102 2005), tryptophan is linked to kynurenine production (Knox and Mehler, 1950), and lysine to $\alpha$ -

103 aminoadipic acid (Borsook et al., 1948). As such, we argue that the elevation essential amino

104 acids and concomitant increase in levels of their amino acid-specific breakdown products may

105 indicate a physiological need for fish to increase the oxidation of these specific amino acids for

106 energy, over preferential recycling of essential amino acids back into protein.

To assess possible biomarkers of protein degradation, our strategy focused on 'post-

108 translational' protein modifications, which are physical changes to amino acids following their

109 incorporation into a protein molecule. These post-translational modifications are in some cases

110 retained by the amino acid following degradation of the protein back to free amino acids (Figure

111 2). Thus the presence of these modified amino acids in blood may act as potential markers of

112 protein breakdown. Here, we focus on three modified amino acids: hydroxyproline, a major

113 constituent of collagen (Stetten, 1949; Prockop and Sjoerdsma, 1961), dimethylarginines, which

114 are enzymatic modifications of arginine (Vallance and Leiper, 2004), and methionine sulfoxide,

115 which is a non-enzymatic modification of methionine that can occur in 4-8\% of all methionine

116 found within proteins (Stadtman et al., 2005). The proteinaceous origin of these post-

117 translationally modified metabolites may thus elucidate the relative rate of protein degradation in

118 walleye from different areas of Lake Winnipeg (see Figure 2). 


\section{Linking metabolites and spatial patterns}

121 In the present study, we examined both temporal and spatial changes in Lake Winnipeg

122 walleye morphological measurements using gillnet index data collected by the Province of

123 Manitoba. First, length-at-age was used to assess longer-term trends in growth prior to 2017.

124 Differences in walleye length-at-age may be an effective metric to study the historical rainbow

125 smelt collapse (approximately 2013), since length-at-age is a summary of prior growth while

126 nutritional deprivation has little effect on length (Caruso et al., 2011; Einen and Thomassen,

127 1998; Sumpter et al., 1991). On the other hand, body condition or length-mass relationships can

128 vary with a single spawning or feeding event, each of which change a fish's mass. Spatial

129 patterns in length-at-age $(\approx$ growth rate) and length-mass relationships $(\approx$ body condition $)$ are

130 thus assessed concurrently. We then linked length-mass relationships to a survey of walleye in

131 Lake Winnipeg in 2017, where blood was sampled non-lethally for metabolites included in our

132 nutritional biomarker development strategy (see above; Figure 2). Spatial differences in the

133 presence of chosen metabolites were then tested with estimated marginal means (Lenth, 2019;

134 Searle et al., 1980) and linear models incorporating length and site collected. We hypothesized

135 that because the rainbow smelt collapse was most pronounced in the north basin of Lake

136 Winnipeg (Manitoba Government, 2018), north basin walleye would exhibit the greatest decline

137 in relative mass over time and length-at-age. We also hypothesized that metabolites would

138 implicate higher rates of endogenous protein breakdown (i.e., elevated hydroxyproline,

139 dimethylarginine, and methionine sulfoxide) and amino acid oxidation (i.e., elevated dimethyl

140 sulfone, kynurenine, and $\alpha$-aminoadipic acid) in the north basin than in the south basin. This

141 work thus 1) explored the effect of the rainbow smelt collapse on Lake Winnipeg walleye

142 morphology and 2) examined the potential for a suite of 9 metabolites to reflect walleye

143 nutritional status and be developed into a non-lethal sampling approach for assessing the

144 nutritional state of wild-caught fish.

146 Methods 
We used the Lake Winnipeg gillnet index data collected by the Government of Manitoba

149 between 2009 and 2018 (data accessed September 2019:

150 https://www.gov.mb.ca/sd/fish_and_wildlife/fish/commercial_fishing/netting_data.html). This

151 gillnet index has been run annually by the province since 1979 to provide an alternative to

152 commercial fisheries data to better track trends in size and abundance for walleye and sauger

153 (Sander canadensis) in Lake Winnipeg. We focused on the data collected between 2009 and

1542018 because there was consistent monitoring of the same six sites during that period and these

155 data included age estimates for each fish. To examine walleye length-mass and length-at-age

156 relationships over time, sauger and dwarf walleye (which possibly inhabit a different ecological

157 niche and are responding to selective pressures; see Moles et al., 2010) were filtered out. The

158 remaining data set included year, site, basin collected, gillnet mesh size, fork length, mass, and

159 sex for adult and sub-adult walleye. Fork length and mass were transformed on a $\log _{10}$ scale.

160 Gillnet mesh size was included as an independent variable where possible to account for bias in

161 walleye length and mass caught in gillnets with different mesh sizes. For all linear models, we

162 chose variables based on their biological significance, as opposed to taking a stepwise model

163 selection approach. Statistical modeling was performed in R (R Core Team, 2019) using the

164 packages emmeans (Searle et al., 1980), sjstats (Lüdecke, 2019), and tidyverse (Wickham et al.,

165 2019). Scripts used for all statistical analyses in this study are available at:

166 https://github.com/BioMatt/walleye_condition_metabolites.

169 Changes in growth rate over time were assessed for walleye from seven sites across Lake

170 Winnipeg using length-at-age data from the gillnet index, with a special focus on growth rates

171 before and after the rainbow smelt collapse (in approximately 2013). Length is a useful measure

172 because a fish facing nutritional deprivation decreases in mass, but decreases in length either

173 negligibly or not at all (Caruso et al., 2011; Einen and Thomassen, 1998; Sumpter et al., 1991).

174 Length-at-age therefore represents more long-term trends in growth than year-specific values for

175 body condition or length-mass relationships. A separate linear model was used for each site

176 sampled for the gillnet index data, with Dauphin River and Grand Rapids representing the north

177 basin, Matheson Island and Frog Bay representing the channel, and Riverton and Grand Beach 
178

representing the south basin of Lake Winnipeg (Figure 1). These linear models used fork length as the dependent variable, and the independent variables were age interacting with year, sex, and gillnet mesh size. Results were therefore averaged over gillnet mesh sizes to account for sampling bias. Only walleye ages two through six years old as estimated by counting annuli in otoliths were included in the models, because not all sites had sufficient sample sizes available for walleye of older and younger ages $\left(n \geq 10\right.$ individuals age class ${ }^{-1}$ year $^{-1}$ site $^{-1}$, except the Dauphin River age two fish in 2012 and 2014 were included, $n=5$ and 2, respectively). A total of $n=2164$ individuals were used in the models for Dauphin River, $n=2745$ for Grand Rapids, $n=844$ for Matheson Island, $n=959$ for Frog Bay, $n=1732$ for Riverton, and $n=1729$ for Grand Beach collection sites.

Differences in walleye growth rates (i.e., length-at-age) among sampling sites were also examined for the years surrounding 2017 (i.e., 2015-2018), to support connections with the available metabolite data (i.e., from year 2017) and thus potential food availability during this time. Age two and three walleye sampled in 2018 were of particular interest for this analysis because length-at-age for young walleye in the growth phase of their life cycle in 2018 should reflect food availability from 2017 through to their capture in 2018. Four similar linear models (i.e., one for each year) were used for length-at-age comparisons among sites. In each model, fork length was the dependent variable, while independent variables were the interaction of site and age, sex, and gillnet mesh size. As above, only walleye ages two through six years old were included in the models. For these analyses, $n=1844$ individuals were available for the year 2015, $n=1392$ for $2016, n=805$ for 2017 , and $n=624$ for 2018 . Estimated marginal means and estimated marginal trends were used to investigate pairwise mean and slope differences between sites for each model (Lenth, 2019; Searle et al., 1979). Briefly, the analysis of estimated marginal means obtains predictions from a linear model using Tukey's post hoc test and finds meaningful averages to summarize primary factor effects while estimated marginal trends follows the same process but for the interaction between two predictors in a model (see Lenth, 2019).

\section{Lake Winnipeg Walleye Relative Mass Over Time}

Relative mass over time was examined for walleye across Lake Winnipeg. These relative mass measures were used as metrics analogous to body condition, which is an imperfect 
approach to our data because walleye mass may change in a single feeding or spawning event, thus changing a fish's body condition and length-mass relationship. However, an examination of relative mass remains useful because it represents a link between inter-annual growth rate trends

211 and metabolite presence, which can vary on much faster timescales. Only walleye $\geq 375 \mathrm{~mm}$ in

212 fork length from the gillnet index data, $n=5,838$ individuals (mean 583.80 walleye \pm 220.17 s.d.

213 year $^{-1}$ ), were included in the model because this value represents the smallest estimate of fork

214 length for mature individuals among Manitoba lakes (Craig et al., 1995), and is a conservative

215 threshold for modeling the fish that were sampled for metabolites (minimum fork length 452

$216 \mathrm{~mm}$ ). After filtering, a total of $n=5,838$ individuals (mean 583.80 walleye \pm 220.17 s.d. $^{2}$ year $^{-1}$ )

217 remained.

218 To study how relative mass has changed over time, a linear model was used with mass as 219 the dependent variable, and independent variables were fork length and its interactions with site,

220 year and sex. Eta squared is reported for the independent variables in this model, where analysis

221 of variance applied to the model outputs returns the percentage of variance in the final model

222 accounted for by an independent variable (Levine and Hullett, 2002).

In addition to exploring length-mass relationships over time, we modeled spatial

226 relationships among Lake Winnipeg walleye using the gillnet index data set in 2017 to establish

227 possible connections between length-mass relationships and metabolite presence in that year.

228 Here, $n=286,127$, and 227 individuals remained from the Dauphin River, Matheson Island, and

229 Riverton sites, respectively. These three sites were chosen because they are most similar to the

230 three sites sampled for metabolites (i.e. Dauphin River, Matheson Island, and the Red River).

231 This model used mass as the dependent variable, with the independent variables as the

232 interaction of mass with fork length, site collected, sex, age, and gillnet mesh size.

233 Another linear model was used to assess the length-mass relationship of walleye caught

234 as part of the blood metabolite study in 2017. The smallest walleye in this data set was $452 \mathrm{~mm}$

235 in fork length. Mass was the dependent variable, with the independent variables fork length

236 interacting with site collected, sex, and the interaction of fork length and sex. Note that gillnet 
mesh size and age were not included in the model since fish were caught by electrofishing and age was not known for these fish.

To examine how similar the length-mass relationships were of walleye were between those collected for metabolite analysis and those for the gill net index data, we used a linear model with an independent variable describing which study an individual was collected for.

242 Here, mass was the dependent variable, which was related to fork length, basin collected, sex,

243 study (metabolite or gillnet index), the interaction of fork length and basin, the interaction of fork

244 length and sex, and the interaction between fork length and study. In this model, only gillnet

245 index samples from the Dauphin River, Matheson Island, and Riverton were included. Riverton

246 from the gillnet index data and the Red River from the metabolite data were used to jointly

247 represent the south basin of Lake Winnipeg.

In 2017, 39 walleye were collected from three sampling locations: the Red River,

251 Matheson Island and Dauphin River representing the south basin, channel, and north basin of

252 Lake Winnipeg, respectively (Figure 1). Each sampling location was at a known spawning site

253 during spawning season (May $2^{\text {nd }}$ in the Red River, May $17^{\text {th }}$ and $18^{\text {th }}$ at Matheson Island, and

254 May $29^{\text {th }}$ through $31^{\text {st }}$ at the Dauphin River). Measured metabolites may thus have been affected

255 by the approximately one-month range in sampling. In addition, we could not verify that sampled

256 individuals had spawned at their collection site, or if they had spawned elsewhere and moved to

257 the collection site. Both males and females were collected, with $n=17$ from the Red River (2

258 males, 15 females), $n=5$ from Matheson island ( 2 males, 3 females), and $n=17$ from the Dauphin

259 River (5 males, 12 females), and had a minimum mass of 1 kilogram (mean $2.32 \mathrm{~kg} \pm 0.97$ s.d.).

260 Individuals were collected by boat electrofishing, held in a live well for no longer than one hour,

261 and anaesthetized using a Portable Electroanesthesia System (PES ${ }^{\mathrm{TM}}$, Smith Root, Vancouver,

262 Washington, USA) in accordance with approved animal use protocols of Fisheries and Oceans

263 Canada (FWI-ACC-2017-001, FWI-ACC-2018-001), the University of Manitoba (F2018-019)

264 and the University of Nebraska-Lincoln (Project ID: 1208). 
One milliliter of whole blood was collected for metabolite analysis from anaesthetized walleye by caudal puncture using a heparinized needle and $3 \mathrm{ml}$ syringe, flash frozen in liquid nitrogen immediately after sampling, and stored at $-80^{\circ} \mathrm{C}$. Of note, logistics prevented separation a larger study assessing the physiological health, movement, and genetic structure of walleye in Lake Winnipeg. Other tissues collected at the time of blood sampling include a fin clip, gill

271 filaments, the first dorsal spine, scales, and a muscle biopsy. All fish were sampled non-lethally

272 and a VEMCO acoustic tag (VEMCO, Bedford, Nova Scotia, Canada) was surgically implanted 273 prior to release back into the water near the collection site.

Walleye blood samples collected in 2017 (see above) were analyzed using nuclear magnetic resonance (NMR) spectroscopy and a combination of direct injection mass spectrometry with a reverse-phase liquid chromatography with mass spectrometry (DI/LCMS/MS) assay at the University of Alberta Metabolomics Centre TMIC (Edmonton, AB,

280 Canada) as part of a large scale targeted metabolic study. Here we examine a small subset of 281 analytes to identify potential biomarkers of protein degradation and amino acid breakdown as

282 described in Figure 2. Both NMR and DI/LC-MS/MS detected methionine and lysine, so 283 measurements for each metabolite were averaged over the two detection methods. Tryptophan 284 and dimethyl sulfone were only measured by NMR. Kynurenine, hydroxyproline, dimethyl 285 sulfone, and $\alpha$-aminoadipic acid were detected with DI/LC-MS/MS. remove proteins. Filtration, and centrifugation steps were subsequently done to further purify the 288 sample (Psychogios et al., 2011). $250 \mu \mathrm{L}$ of the blood sample was transferred to a $3 \mathrm{~mm}$

289 SampleJet NMR tube for subsequent spectral analysis following a protocol based on Saude et al.

290 (2004). NMR spectra was collected on a $700 \mathrm{MHz}$ Avance III (Bruker) spectrometer and the 291 spectra acquired at $25^{\circ} \mathrm{C}$. NMR spectra were processed and analyzed using the Chenomx NMR 292 Suite Professional software package version 8.1 (Chenomx Inc., Edmonton, AB). DI/LC293 MS/MS was done on an API4000 Qtrap® tandem mass spectrometry instrument (Applied 294 Biosystems/MDS Analytical Technologies, Foster City, CA) equipped with an Agilent 1260 
series HPLC system (Agilent Technologies, Palo Alto, CA). The samples were delivered to the mass spectrometer by a LC method followed by a direct injection (DI) method. Data analysis was done using Analyst 1.6.2.

Differences in nine metabolites across sampling sites were assessed using separate linear models. Dimethyl sulfone, kynurenine, $\alpha$-aminoadipic acid, methionine, tryptophan, lysine,

302 hydroxyproline, dimethylarginine, and methionine sulfoxide were used as dependent variables in 303 their respective linear models. For each model, the independent variables were log fork length 304 and site collected. Estimated marginal means of metabolite presence were calculated to establish 305 pairwise significance between sites. Significance for each fork length and site collected were 306 calculated, along with eta squared (Levine and Hullett, 2002) to report effect size for each 307 independent variable.

\section{Results}

\section{Lake Winnipeg Walleye Length-at-Age Over Time}

312 Grand Beach sites exhibited a decline in length-at-age for age six walleye between the years

3132012 and 2018 (Figure 3). However, for the age two and three walleye, while the Dauphin River

314 (north basin) site also showed a shorter length-at-age in 2018 compared to 2012, the south basin

315 sites (Riverton and Grand Beach) showed similar length-at-age in later years (i.e. 2017 and 2018)

316 relative to earlier years (i.e. 2012 and 2013). The Grand Rapids (in the north basin) showed the

317 most consistent decline in length-at-age for all ages over time except for the age two fish

318 sampled in 2017 and 2018 (Figure 3).

Length-at-age decreased for Dauphin River walleye at ages two and three between the

320 years 2017 and 2018 (Figure 3, Figure 4). For length-at-age in 2018 specifically, pairwise

321 estimated marginal means using Tukey's post-hoc test on the linear model $(F=66.81, p<2.2 \mathrm{x}$

$32210^{-16}$, adjusted $R^{2}=0.80$ ) showed significant differences in estimated marginal mean of length- 
323 at-age between the Dauphin River (north basin) and Riverton (south basin), Grand Beach (south

324 basin), and Matheson Island (channel) sites in age two walleye (Table 1). Slopes in length-at-age

325 relationships, as described using estimated marginal trends, were also significantly more steep

326 between the Dauphin River and the Matheson Island, Riverton, and Grand Beach sites,

327 respectively (Table 1, Figure 4). Based on these results, we suggest that young Dauphin River

328 walleye grew more slowly in 2017 than young walleye at the Matheson Island (channel) and the

329 south basin sites.

Lake Winnipeg Walleye Relative Mass Over Time

From the years 2009 through 2018, year, sex, and the interaction between fork length and

333 year had a significant relationship with Lake Winnipeg walleye length-mass relationships $(F=$

$3342899, p<2.2 \times 10^{-16}$, adjusted $R^{2}=0.95$, Table 2$)$. While fork length had the greatest effect size

335 as indicated by eta squared, year had a greater effect size than site collected during the time

336 period studied. Confidence intervals determined using estimated marginal means indicated

337 significant differences among the effect of years on mass, with a drop in predicted mass most

338 noticeable between the years 2014 and 2015 (Figure 5A).

In a linear model using gillnet index data for fish captured in 2017 that were $\geq 375 \mathrm{~mm}$ in

342 fork length and including only the Dauphin River, Matheson Island, and Riverton sites, $(F=222$,

$343 p<2.2 \times 10^{-16}$, adjusted $R^{2}=0.97$ ), estimated marginal mean length-mass relationships were the

344 same for three sites, but estimated marginal trends were lower in the Dauphin River compared to

345 Matheson Island (Table 3; Figure 5B). This suggests a different length-mass relationship for the

346 north basin fish compared to walleye caught in the channel.

347 Similar to the larger fish sampled as part of the gill net index in 2017, for length-mass 348 relationships among walleye collected for metabolites $\left(F=86, p<2.2 \times 10^{-16}\right.$, adjusted $R^{2}=$

349 0.94), estimated marginal trends were also lower in the Dauphin River compared to Matheson

350 Island (Table 3; Figure 5C). However, unlike the linear model used with the gillnet index data, 
the Red River (south basin) showed a higher estimated marginal mean mass than the Matheson Island (channel) site (Table 3; Figure 5C).

When comparing length-mass relationship of larger walleye collected in 2017 as part of the gill net index and metabolite studies, no significant effect of study and of study interacting fork length was found $\left(F=889, p<2.2 \times 10^{-16}\right.$, adjusted $R^{2}=0.97$, Table 4). However, estimated marginal means of mass based on fork length were higher in the walleye from the metabolite data $(p=0.00070)$ while estimated marginal trends for fork length-mass relationships between studies were not different $(p=0.90)$. A plot of fork length and mass with these data reveals that the metabolite-measured walleye lie at the upper end of the distribution in length-mass for walleye collected for the gillnet index data, while following a similar slope (Figure 5D).

\section{Modeling Metabolites Differences}

Metabolite presence of the three essential amino acids varied significantly across sampling sites for Lake Winnipeg walleye sampled in 2017. The models predicting the presence of each of the three free essential amino acids were each significant $(F=4.3,4.7$, and 3.7, $p=$ $0.011,0.0071$, and 0.020 , adjusted $R^{2}=0.21,0.23$, and 0.18 for methionine, tryptophan, and

367 lysine respectively, Table 5). In addition, site was a significant independent variable within the 368 overall models for the three essential amino acids while fork length was not, with eta squared 369 higher for site than for fork length in each case (Table 5). Estimated marginal means for each of 370 the three essential amino acids revealed significant differences in predicted essential amino acid 371 presence based on site, with higher values in the Dauphin River (north basin) than in the Red 372 River (south basin) (Figure 6A, B, and C).

374 essential amino acid breakdown biomarkers. Linear models for $\alpha$-aminoadipic acid, kynurenine, 375 and dimethyl sulfone were not significant $(F=0.32,2.6$, and 3.3, $p=0.81,0.070$, and 0.031, 376 adjusted $R^{2}=0.057,0.11$, and 0.15 , respectively, Table 5), indicating a failure to fit fork length 377 and site to essential amino acid breakdown metabolite presence. The model for dimethyl sulfone

378 was significant ( $p=0.031)$, but neither site nor fork length were significant independent 379 variables ( $p=0.36$ and 0.088 , respectively). Predicted metabolite presence from estimated 
marginal means showed no significant differences in amino acid breakdown metabolites among sites, as well (Figure 6D, E, and F). site in Lake Winnipeg walleye sampled in 2017. Linear models run with hydroxyproline,

384 dimethylarginine, and methionine sulfoxide, potential endogenous protein breakdown

385 biomarkers, were each significant $\left(F=24.12,6.2\right.$, and 6.3, $p=1.2 \times 10^{-8}, 0.0017$, and 0.0016,

386 adjusted $R^{2}=0.65,0.29$, and 0.29, respectively, Table 5). Moreover, site collected was both a

387 significant independent variable and had a higher effect size than fork length in each model

388 (Table 5). Predicted presence for each candidate metabolite associated with protein breakdown was higher in the northern Dauphin River than the southern Red River (Figure 6G, H, and I).

390 Hydroxyproline and dimethylarginine were also higher in fish from the Dauphin River than at

391 Matheson Island in the channel.

\section{Discussion}

394 In the current study, we aimed to understand how changing food availability may be 395 affecting walleye and could potentially contribute to large-scale changes in the size and 396 abundance of walleye that have been observed in Lake Winnipeg in recent years. We used the 397 Lake Winnipeg gillnet index data set to examine length-at-age and relative mass to assess trends 398 in the growth of walleye from 2009 to 2018. The decreases in walleye mass appeared to coincide

399 with the near complete collapse of the rainbow smelt population in 2013 as there was a

400 significant drop in relative mass (analogous to body condition) at all sites in the gillnet index

401 between 2014 and 2015. The pattern of overall decrease in mass remained in fish collected in the 402 index until 2018, the last year of data available at the time of analyses. We attempted to control 403 for as many possible confounding variables in the analyses, however the overall trend showed a 404 decrease in relative mass regardless of sex or gillnet mesh size, a pattern that is consistent with 405 previous analyses (Manitoba Government, 2018). Contrary to our predictions, the general trend 406 of decreasing relative mass was not more severe in the north basin (see Figure 5A) where 407 rainbow smelt contributed to a larger portion of the diet of walleye (Sheppard et al., 2015).

408 Given that the decrease in relative mass occurred at all sites sampled, these data suggest 
ecosystem-wide changes in Lake Winnipeg have contributed to decreases in walleye size over the past decade.

411 Length-at-age estimates were used as a more stable measurement of changes in growth

412 patterns between 2009 and 2018 because it is less variable than measures of mass that can

413 fluctuate more rapidly (e.g., pre- and post-spawning, post-overwintering). Interestingly, there

414 was a pattern of decreased length in two-year old fish over time, which was most dramatic for

415 fish caught at the Dauphin River site between 2017 and 2018. Reduced food availability or an

416 increase in energetic costs in 2016 and 2017 for young fish at the Dauphin River may have led to

417 this decreased length-at-age. At all sites in the gillnet index, there was also an overall decrease in

418 the length of 6-year old fish from 2016 to 2018. The pattern of decreased length in fish was most

419 prominent in fish collected at the most northern site sampled, Grand Rapids. We believe that this

420 decrease in fish growth in later years (i.e., 2016-2018) of the six-year-old fish may represent a

421 delayed effect from an earlier large-scale change in the ecosystem (e.g., collapse of the rainbow

422 smelt population in 2013). The decrease in the length at age in older fish may have further

423 impacts on walleye abundance in Lake Winnipeg as the length of fish and fecundity is highly

424 correlated (Craig et al., 1995; Wolfert, 1969). Therefore, the population-level impacts of the

425 decrease in the size of walleye in Lake Winnipeg may become a bigger issue in the future.

426 While the present study is focused on the collapse of the rainbow smelt, additional 427 differences between basins may underlie observed spatial patters. Some of these basin-level

428 differences include higher temperatures, precipitation, river discharge, suspended solids,

429 sulphate, phosphorous, and nitrogen in the south relative to the north basin (Environment

430 Canada, 2011). Phosphorous loading and summer surface temperatures may contribute to algal

431 blooms, which were more prevalent in the south basin (Binding et al., 2018; Environment

432 Canada, 2011). Meanwhile, sodium and chloride are twice as high in the north than in the south,

433 likely because of inflow from the Dauphin River (Environment Canada, 2011). Prey fish

434 populations other than the rainbow smelt also differ spatially, with emerald shiner (Notropis

435 atherinoides) and cisco (Coregonus artedi) more abundant in the south basin (between 2002-

436 2008) as well as in the diets of south basin walleye (in 2010 and 2011) (Lumb et al., 2012;

437 Sheppard et al., 2015). When these differences between basins are considered in conjunction

438 with data showing that rainbow smelt did not historically make up the entirety of walleye diets 
439 (Sheppard et al., 2015), it becomes clear that the rainbow smelt collapse is one of many potential

440 factors that have affected walleye growth. Nevertheless, the disparity in growth rate (length-at-

441 age) between basins, the higher abundance of rainbow smelt in the north basin, and its

442 prevalence in north basin walleye diets in 2010 and 2011 (Sheppard et al., 2015) despite high

443 walleye connectivity between basins (Backhouse-James and Docker, 2011; Thorstensen et al.,

444 2020) suggests the rainbow smelt collapse had a large effect on the Lake Winnipeg walleye

445 fishery.

Metabolites

We observed from a preliminary analysis of a large-scale targeted metabolomics study

449 (with 163 unique metabolites) that essential amino acids varied in whole blood from walleye

450 caught from different regions of Lake Winnipeg (Wiens, Jeffrey, Treberg unpublished data),

451 which provided the impetus to pursue the nutritional biomarkers strategy that we employed in the

452 current study. We focused on three essential amino acids (methionine, tryptophan and lysine),

453 that were each elevated in the Dauphin River fish relative to the more southern Red River fish

454 (Figure 6). Whole blood was necessary because it was not possible to separate plasma or serum

455 in the field, and we therefore cannot distinguish between differences at the cellular level (mainly

456 red blood cells), or extracellular component of blood. Despite this limitation, because blood acts

457 as a connection between all organs and tissues, we are nevertheless confident that the more north

458 basin walleye had elevated essential amino acids in circulation.

459 Interpretation of changes in circulating levels of amino acids is complicated by the

460 dynamic nature of amino acid levels in the blood. Most fish nutritional studies focus on the

461 plasma (extracellular component) of blood, and show that essential amino acids may be high due

462 to two mutually exclusive reasons. During periods of high feeding success, the removal of

463 circulating amino acids may not be sufficient to prevent the amino acid levels from elevating in

464 the circulation. In other words, high amino acid levels can reflect high food intake. Alternatively,

465 if the animal must rely on increased protein breakdown due to insufficient feeding, then

466 circulating levels of essential amino acids may also increase (Blasco et al., 1991; Schuhmacher et

467 al., 1995; Costas et al., 2011). 
That north basin fish in 2017 displayed lower length-at-age, or less growth, indicates the northern fish may have had lower feeding success in that year compared to the faster growing south basin walleye (Figure 4). Even though the growth estimates support the idea that higher amino acid levels do not reflect greater feeding success for 2017, more information is needed to

472 provide sufficient context for interpreting plasma amino acid levels. Our metabolite screening 473 yielded results for metabolites specific to the degradation pathways each of the three essential 474 amino acids we found to be elevated in the blood of Northern basin fish (Figure 6D, E, and F).

475 Animals use each specific amino acid for energy metabolism by committing each amino acid to 476 its specific degradation pathway. Elevated levels in the metabolites of amino acid degradation

477 therefore imply increased oxidation of each amino acid. Thus, we use these degradation 478 metabolites (dimethyl sulfone, kynurenine, $\alpha$-aminoadipic acid) as three independent tests of whether or not essential amino acids are being directed towards energy metabolism. In all cases, there was no difference in the metabolites of amino acid oxidation across sampling site. Since most amino acid oxidation takes place outside of the blood (Jürss and Bastrop, 1995; Ballantyne, 2001), one caveat is that blood levels of these metabolites may not sufficiently reflect true whole

483 animal amino acid oxidation. For that reason, the possibility that elevated amino acids reflect a

484 greater reliance on amino acids as energy sources in the Dauphin River fish cannot be outright 485 rejected. However, taken together with the lower growth in the north basin walleye in 2017, we 486 can conclude that it is unlikely the northern walleye have less reliance on protein oxidation than 487 south basin walleye.

Because we focused on amino acids in the blood, and protein turnover is a major source of those circulating amino acids, we needed a means to investigate spatial patterns of protein

490 degradation. To distinguish between amino acids in general and those amino acids that have 491 already been incorporated into proteins, we focused on amino acids that have been modified after 492 they were incorporated into proteins. Three unique protein modifications that arise from three 493 separate routes are focused on: two that come from enzymatic processes (hydroxyproline and 494 dimethylarginine), and one that occurs spontaneously as exposed methionines are oxidized by 495 reactive molecules such as hydrogen peroxide (methionine sulfoxide). While methionine 496 sulfoxide can be formed from free methionine, most methionine from tissues is bound in 497 proteins, so we assume that the bulk of circulating methionine sulfoxide is of proteinaceous 498 origin. Because the means of forming these three post-translational modifications from amino 
acids represent independent pathways, we had no a priori expectation that the levels of all three

500 post-translational modifications would be observed to vary in a consistent fashion across Lake

501 Winnipeg. Nevertheless, all three modifications were higher in fish from the north than the south

502 basin (Figure 6G, H, and I). The signal of protein degradation, based on the consistent presence

503 of post-translationally modified amino acids, could therefore suggest a higher rate of protein

504 turnover in walleye from the north basin of Lake Winnipeg than the south.

505 If an increased reliance on protein oxidation for energy is not driving the elevated amino

506 acids in north basin fish, then the question remains of why there was an increase in protein

507 turnover in those northern fish. While protein metabolism is controlled by many factors, both

508 protein synthesis and degradation rates in fish are known to increase with the level of swimming

509 activity (Houlihan and Laurent, 1987). If the north basin walleye must spend more time

510 swimming to find sufficient nutritional resources, then elevated levels of post-translationally

511 modified amino acids could reflect a greater level of activity for the fish in the north. Relevant to

512 these results, and contrary to what may be intuitive for carnivorous fishes, careful estimations of

513 fuel usage in relation to swimming speed indicates that protein is likely not a major fuel source

514 to supply the increased energy demand of increased swimming in rainbow trout and Nile Tilapia

515 during short-term swimming (Alsop and Wood, 1997; Alsop et al., 1999); although, using the

516 same strategies in Nile Tilapia indicated that prolonged swimming (at $\sim 2.7$ body lengths/second)

517 over the course of over 48 hours did increase the relative reliance on protein to fuel swimming in

518 unfed fish (Alsop et al., 1999). Since walleye in the wild appear to spend most of their time

519 swimming at speeds below 1.0 body lengths/second (Kelso, 1978), it seems that the extended

520 swimming response in tilapia is not likely applicable to the walleye sampled from the wild in the

521 present study. We therefore suggest that elevated signals of protein turnover in wild walleye may

522 be due to increased swimming activity, which may be undertaken to compensate for decreased

523 food availability.

Linking Data Sets

The metabolite and gillnet index datasets were consistent in patterns of possible

527 decreased food availability in the north basin in 2017 (when metabolites were measured), based

528 on analyses of spatially varying growth rates in the 2017 gillnet index data and slopes of length- 
mass relationships in both datasets. Moreover, data set origin (gillnet index or metabolite-

530 measured walleye captured via electrofishing) was not a significant predictor of overall length-

531 mass relationship in a combined linear model, providing additional evidence for no systematic

532 bias in length-mass relationship in one data set or another, even if the walleye used for

533 metabolites were large. Altogether, we argue that the walleye used for assessing metabolite

534 levels are likely representative of large walleye captured in the gillnet index data, and that spatial

535 differences in the slopes of length-mass relationships ( $\approx$ body condition) and length-at-age $(\approx$

536 growth rate) are consistent with spatially varying metabolite presence.

537 The time scale in response variables should be considered when relating ecology to length-at538 age, length-mass relationships, and metabolite levels across data sets. Length-at-age estimates

539 are summaries of one or more prior years of growth for a cohort of walleye, while mass may

540 change from a single feeding or spawning event, thus changing length-mass relationships. In

541 addition, while we do not have information for the response time of amino acids or their

542 metabolites, other metabolites such as blood glucose and lactate increased with handling on a

543 timescale of minutes, indicating that amino acid metabolite presence may also reflect the past

544 several minutes of a fish's life as opposed to ecological patterns (Chopin et al., 1996; Grutter and

545 Pankhurst, 2000; Meka and McCormick, 2005; Lawrence et al., 2018). However, the consistency

546 in patterns across timescales — stronger signals of protein breakdown, more shallow length-mass

547 relationships, and slower growth in the north basin in 2017-supports the validity of this

548 approach for integrating data from different levels of biological organization. The breadth in

549 timescales analyzed may also be a benefit for integrating information across data sets because

550 each piece of information provides context for other results.

552 Conclusions

554 in recent years, especially those in the north basin. These morphological differences are

555 consistent with both the collapse of the rainbow smelt population and blood metabolites,

556 suggesting increased endogenous protein breakdown in the north basin. With validation and

557 refinement, the metabolites identified in the present study thus have potential for further

558 development into molecular markers possibly useful as indicators of nutritional status for the 
walleye fishery. Molecular indicators of nutritional status would be valuable tools for resource managers for describing physiological thresholds in nutritional status that are predictive of

561 detrimental effects on the walleye fishery (Connon et al., 2018). In other words, a molecular

562 panel describing nutritional status may support the sustainable management of the Lake

563 Winnipeg fishery.

Acknowledgments

We thank E. Enders, D. Watkinson, C. Charles, C. Kovachik, D. Leroux, N. Turner, M. Gaudry, S. Glowa, and E. Barker for their role in sampling the walleye used for metabolites. C.

568 Charles and E. de Greef assisted with a map of Lake Winnipeg, and E. de Greef also provided

569 immense support in the process of writing the manuscript. This work was supported by a

570 Fisheries and Oceans Canada Ocean and Freshwater Science Contribution Program Partnership

571 Fund grant awarded to J.R.T., K.M.J. and Darren Gillis, and Natural Sciences and Engineering

572 Research Council of Canada Discovery Grants awarded to K.M.J. (\#05479) and J.R.T. (\#06052).

573 Work by J.R.T. is also supported by the Canada Research Chairs program (\#223744) and the

574 Faculty of Science, University of Manitoba (\#319254).

\section{References}

Alsop, D.H., Kieffer, J.D., Wood, C.M., 1999. The effects of temperature and swimming speed on instantaneous fuel use and nitrogenous waste excretion of the Nile tilapia. Physiological and Biochemical Zoology 72, 474-483. https://doi.org/10.1086/316686

580 Alsop, D.H., Wood, C.M., 1997. The interactive effects of feeding and exercise on oxygen consumption, swimming performance and protein usage in juvenile rainbow trout (Oncorhynchus mykiss). Journal of Experimental Biology 200, 2337-2346.

Backhouse-James, S.M., Docker, M.F., 2012. Microsatellite and mitochondrial DNA markers show no evidence of population structure in walleye (Sander vitreus) in Lake Winnipeg. Journal of Great Lakes Research 38, 47-57. https://doi.org/10.1016/j.jglr.2011.05.005 5098(01)20004-1 
Binding, C.E., Greenberg, T.A., McCullough, G., Watson, S.B., Page, E., 2018. An analysis of satellite-derived chlorophyll and algal bloom indices on Lake Winnipeg. Journal of Great Lakes Research 44, 436-446. https://doi.org/10.1016/j.jglr.2018.04.001

Black, D., Love, R.M., 1986. The sequential mobilisation and restoration of energy reserves in tissues of Atlantic cod during starvation and refeeding. Journal of Comparative Physiology B 156, 469-479. https://doi.org/10.1007/BF00691032

Blasco, J., Fernández, J., Gutiérrez, J., 1991. The effects of starvation and refeeding on plasma amino acid levels in carp, Cyprinus carpio L., 1758. Journal of Fish Biology 38, 587-598. https://doi.org/10.1111/j.1095-8649.1991.tb03145.x

Borsook, H., Deasy, C.L., Haagen-Smit, A.J., Keighley, G., Lowy, P.H., 1948. The degradation of l-lysine in guinea pig liver homogenate; formation of alpha-aminoadipic acid. The Journal of biological chemistry 176, 1383-93.

600 Carter, C.G., Houlihan, D.F., 2001. Protein synthesis. pp. 31-75. https://doi.org/10.1016/S15465098(01)20003-X

602 Caruso, G., Denaro, M.G., Caruso, R., Mancari, F., Genovese, L., Maricchiolo, G., 2011.

603 Response to short term starvation of growth, haematological, biochemical and non-specific immune parameters in European sea bass (Dicentrarchus labrax) and blackspot sea bream (Pagellus bogaraveo). Marine Environmental Research 72, 46-52. https://doi.org/10.1016/j.marenvres.2011.04.005

Caskanette, A., Watkinson, D., Enders, E.C., 2020. The rise and fall of Rainbow Smelt. Journal

Chopin, F.S., Arimoto, T., Inoue, Y., 1996. A comparison of the stress response and mortality of sea bream Pagrus major captured by hook and line and trammel net. Fisheries Research 28, 277-289. https://doi.org/10.1016/0165-7836(96)00512-7

Collins, A.L., Anderson, T.A., 1995. The regulation of endogeneous energy stores during starvation and refeeding in the somatic tissues of the golden perch. Journal of Fish Biology 47, 1004-1015. https://doi.org/10.1111/j.1095-8649.1995.tb06024.x

Connon, R.E., Jeffries, K.M., Komoroske, L.M., Todgham, A.E., Fangue, N.A., 2018. The utility of transcriptomics in fish conservation. Journal of Experimental Biology 221. https://doi.org/10.1242/jeb.148833 J.M., Conceição, L.E.C., 2011. Feed deprivation in Senegalese sole (Solea senegalensis Physiology and Biochemistry 37, 495-504. https://doi.org/10.1007/s10695-010-9451-2 
Craig, J.F., Babaluk, J.A., Stevenson, S.G., Williams, P.C., 1995. Variation in growth and reproduction of walleye (Stizostedion vitreum) in three Manitoba lakes. Canadian Journal of Zoology 73, 367-372. https://doi.org/10.1139/z95-040

Dudgeon, D., Arthington, A.H., Gessner, M.O., Kawabata, Z.I., Knowler, D.J., Lévêque, C., Naiman, R.J., Prieur-Richard, A.H., Soto, D., Stiassny, M.L.J., Sullivan, C.A., 2006. Freshwater biodiversity: Importance, threats, status and conservation challenges. Biological Reviews of the Cambridge Philosophical Society 81, 163-182. https://doi.org/10.1017/S1464793105006950

Einen, O., Thomassen, M.S., 1998. Starvation prior to slaughter in Atlantic salmon (Salmo salar). II. White muscle composition and evaluation of freshness, texture and colour characteristics in raw and cooked fillets. Aquaculture 169, 37-53. https://doi.org/10.1016/S0044-8486(98)00332-9

Engelke, U.F.H., Tangerman, A., Willemsen, M.A.A.P., Moskau, D., Loss, S., Mudd, S.H., Wevers, R.A., 2005. Dimethyl sulfone in human cerebrospinal fluid and blood plasma confirmed by one-dimensional $1 \mathrm{H}$ and two-dimensional $1 \mathrm{H}-13 \mathrm{C}$ NMR. NMR in Biomedicine 18, 331-336. https://doi.org/10.1002/nbm.966

Enders, E.C., Lumb, C., Charles, C., Watkinson, D., 2020. Temporal and spatial variations in the pelagic fish community of Lake Winnipeg. Journal of Great Lakes Research in this issue.

Environment Canada, 2011. State of Lake Winnipeg: 1999 to 2007.

Fisheries and Oceans Canada, 2018. Freshwater Landings [WWW Document]. URL https://www.dfo-mpo.gc.ca/stats/commercial/land-debarq/freshwater-eaudouce/2017eng.htm (accessed 12.20.19).

Gattuso, J.P., Magnan, A., Billé, R., Cheung, W.W.L., Howes, E.L., Joos, F., Allemand, D., 
Houlihan, D.F., Laurent, P., 1987. Effects of Exercise Training on the Performance, Growth, and Protein Turnover of Rainbow Trout (Salmo gairdneri). Canadian Journal of Fisheries and Aquatic Sciences 44, 1614-1621. https://doi.org/10.1139/f87-195

Jürss, K., Bastrop, R., 1995. Chapter 7 Amino acid metabolism in fish. pp. 159-189.

Kelso, J.R.M., 1978. Diel rhythm in activity of walleye, Stizostedion vitreum vitreum. Journal of Fish Biology 12, 593-599. https://doi.org/10.1111/j.1095-8649.1978.tb04206.x

Knox, W.E., Mehler, A.H., 1950. The conversion of tryptophan to kynurenine in liver. I. The coupled tryptophan peroxidase-oxidase system forming formylkynurenine. The Journal of biological chemistry 187, 419-30.

Lawrence, M.J., Jain-Schlaepfer, S., Zolderdo, A.J., Algera, D.A., Gilmour, K.M., Gallagher, A.J., Cooke, S.J., 2018. Are 3 minutes good enough for obtaining baseline physiological samples from teleost fish? Canadian Journal of Zoology 96, 774-786.

673 Lenth, R., 2019. emmeans: Estimated Marginal Means, aka Least-Squares Means. R package 674 version 1.4.3.01.

Levine, T.R., Hullett, C.R., 2002. Eta Squared, Partial Eta Squared, and Misreporting of Effect Size in Communication Research. Human Communication Research 28, 612-625. https://doi.org/10.1093/hcr/28.4.612

Lüdecke, D., 2019. sjstats: Statistical Functions for Regression Models (Version 0.17.7). https://doi.org/10.5281/zenodo.1284472

Lumb, C.E., Franzin, W.G., Watkinson, D.A., 2012. Temporal and spatial patterns in pelagic trawl fish catches in Lake Winnipeg. Journal of Great Lakes Research 38, 14-25. https://doi.org/10.1016/j.jglr.2011.07.008

Manitoba Government, 2018. Fish Populations, Lake Winnipeg Basin Indicator Series. URL https://www.gov.mb.ca/sd/pubs/fish_wildlife/fish/indicators_fishpop.pdf

Manitoba Sustainable Development, 2018. Manitoba Sustainable Development Annual Report

Meka, J.M., McCormick, S.D., 2005. Physiological response of wild rainbow trout to angling: 2017-2018. Winnipeg. URL https://www.gov.mb.ca/sd/pubs/annualreports/annual_report_2017_18.pdf impact of angling duration, fish size, body condition, and temperature. Fisheries Research 72, 311-322. https://doi.org/10.1016/j.fishres.2004.10.006 Leggett, W.C., 2010. Morphological and trophic differentiation of growth morphotypes of 
walleye (Sander vitreus) from Lake Winnipeg, Canada. Canadian Journal of Zoology 88, 950-960. https://doi.org/10.1139/Z10-062

Prockop, D.J., Sioerdsma, A., 1961. Significance of Urinary Hydroxyproline in Man. Journal of Clinical Investigation 40, 843-849. https://doi.org/10.1172/JCI104318

Psychogios, N., Hau, D.D., Peng, J., Guo, A.C., Mandal, R., Bouatra, S., Sinelnikov, I., Krishnamurthy, R., Eisner, R., Gautam, B., Young, N., Xia, J., Knox, C., Dong, E., Huang, P., Hollander, Z., Pedersen, T.L., Smith, S.R., Bamforth, F., Greiner, R., McManus, B., Newman, J.W., Goodfriend, T., Wishart, D.S., 2011. The Human Serum Metabolome. PLoS ONE 6, e16957. https://doi.org/10.1371/journal.pone.0016957

Saude, E.J., Slupsky, C.M., Sykes, B.D., 2006. Optimization of NMR analysis of biological fluids for quantitative accuracy. Metabolomics 2, 113-123. https://doi.org/10.1007/s11306006-0023-5

Schindler, D.W., 2001. The cumulative effect of climate change and multiple stressors. Canadian Journal of Fisheries and Aquatic Sciences 2958, 18-29. https://doi.org/10.1139/f00-179

Schuhmacher, A., Schön, J., Goldberg, M., Gropp, J.M., 1995. Plasma amino acid levels in rainbow trout (Oncorhynchus mykiss). Journal of Applied Ichthyology 11, 309-316. https://doi.org/10.1111/j.1439-0426.1995.tb00032.x

Searle, S.R., Speed, F.M., Milliken, G.A., 1980. Population Marginal Means in the Linear Model: An Alternative to Least Squares Means. The American Statistician 34, 216-221. https://doi.org/10.1080/00031305.1980.10483031

Sheppard, K.T., Davoren, G.K., Hann, B.J., 2015. Diet of walleye and sauger and morphological characteristics of their prey in Lake Winnipeg. Journal of Great Lakes Research 41, 907915. https://doi.org/10.1016/j.jglr.2015.05.006

Sheppard, K.T., Hann, B.J., Davoren, G.K., 2018. Growth rate and condition of walleye (Sander vitreus), sauger (Sander canadensis), and dwarf walleye in a large Canadian lake. Canadian Journal of Zoology 96, 739-747. https://doi.org/10.1139/cjz-2017-0276

Stadtman, E.R., Van Remmen, H., Richardson, A., Wehr, N.B., Levine, R.L., 2005. Methionine oxidation and aging. Biochimica et Biophysica Acta (BBA) - Proteins and Proteomics 1703, 135-140. https://doi.org/10.1016/j.bbapap.2004.08.010

Stetten, M.R., 1949. Some aspects of the metabolism of hydroxyproline, studied with the aid of isotopic nitrogen. The Journal of Biological Chemistry 181, 31-7.

Sumpter, J.P., Le Bail, P.Y., Pickering, A.D., Pottinger, T.G., Carragher, J.F., 1991. The effect of starvation on growth and plasma growth hormone concentrations of rainbow trout, Oncorhynchus mykiss. General and Comparative Endocrinology 83, 94-102. https://doi.org/10.1016/0016-6480(91)90109-J 
Thorstensen, M.J., Jeffrey, J.D., Treberg, J.R., Watkinson, D.A., Enders, E.C., Jeffries, K.M., 2020. Genomic signals found using RNA sequencing support conservation of walleye (Sander vitreus) in a large freshwater ecosystem. bioRxiv. https://doi.org/10.1101/2020.02.07.937961

Vallance, P., Leiper, J., 2004. Cardiovascular Biology of the Asymmetric Dimethylarginine:Dimethylarginine Dimethylaminohydrolase Pathway. Arteriosclerosis, Thrombosis, and Vascular Biology 24, 1023-1030. https://doi.org/10.1161/01.ATV.0000128897.54893.26

Wickham, H., Averick, M., Bryan, J., Chang, W., McGowan, L., François, R., Grolemund, G., Hayes, A., Henry, L., Hester, J., Kuhn, M., Pedersen, T., Miller, E., Bache, S., Müller, K., Ooms, J., Robinson, D., Seidel, D., Spinu, V., Takahashi, K., Vaughan, D., Wilke, C., Woo, K., Yutani, H., 2019. Welcome to the Tidyverse. Journal of Open Source Software 4, 1686. https://doi.org/10.21105/joss.01686

Wolfert, D.R., 1969. Maturity and Fecundity of Walleyes from the Eastern and Western Basins of Lake Erie. Journal of the Fisheries Research Board of Canada 26, 1877-1888. https://doi.org/10.1139/f69-171 
Tables

772 Table 1. $P$-values of pairwise estimated marginal means and trends calculated using Tukey's post 773 hoc test, pulled from a linear model relating $\log _{10}$ fork length to age in interaction with site, sex,

774 and mesh size in the year $2018\left(F=66.81, p<2.2 \times 10^{-16}\right.$, adjusted $\left.R^{2}=0.80\right)$. Means,

775 representing differences in intercepts are above the diagonal and trends, representing differences

776 in slopes are below the diagonal. Estimated marginal means are specific to age two walleye

777 (Sander vitreus), while estimated marginal trends are calculated across all ages between two and

778 six. Data included in this model are from the gillnet index collected by the Government of

779 Manitoba.

780

\begin{tabular}{lllllll}
\hline & $\begin{array}{l}\text { Grand } \\
\text { Rapids }\end{array}$ & $\begin{array}{l}\text { Dauphin } \\
\text { River }\end{array}$ & $\begin{array}{l}\text { Matheson } \\
\text { Island }\end{array}$ & $\begin{array}{l}\text { Frog } \\
\text { Bay }\end{array}$ & Riverton & $\begin{array}{l}\text { Grand } \\
\text { Beach }\end{array}$ \\
\hline $\begin{array}{l}\text { Grand Rapids } \\
\text { Dauphin }\end{array}$ & - & 0.67 & $<0.05$ & 0.24 & $<0.05$ & $<0.05$ \\
$\begin{array}{l}\text { River } \\
\text { Matheson }\end{array}$ & 0.0015 & - & 0.0003 & 0.70 & $<0.05$ & 0.0003 \\
$\begin{array}{l}\text { Island } \\
\text { Frog Bay }\end{array}$ & 0.96 & 0.0035 & - & 0.61 & 0.85 & 1.0 \\
Riverton & 1.0 & 0.96 & 0.40 & - & 0.94 & 0.61 \\
Grand Beach & 0.92 & 0.0002 & 0.94 & 0.67 & - & 0.85 \\
\hline
\end{tabular}


782 Table 2. Results from a linear model describing relative mass over time, relating $\log _{10}$ mass to $783 \log _{10}$ fork length and its interaction with year, site, and sex, with mesh size controlled for $(F=$ $7842899, p<2.2 \times 10^{-16}, R^{2}=0.95$ ). The gillnet index data between the years 2009 and 2018

785 collected by the Government of Manitoba were used for this length-mass model. Only walleye 786 (Sander vitreus) $\geq 375$ millimeters in fork length are included.

787

\begin{tabular}{lll}
\hline & $p$-value & eta squared \\
\hline $\log _{10}$ Fork Length & $<0.05$ & 0.25 \\
Year & $<0.05$ & 0.0080 \\
Site & 0.11 & 0.0010 \\
Sex & 0.040 & 0.0 \\
Mesh Size & $<0.05$ & 0.020 \\
$\log _{10}$ Fork Length * Year & $<0.05$ & 0.0070 \\
$\log _{10}$ Fork Length * Site & 0.16 & 0.0010 \\
$\log _{10}$ Fork Length $*$ Sex & 0.053 & 0.0 \\
\hline
\end{tabular}


Table 3. $P$-values of pairwise estimated marginal means and trends between either basins or sites for two different linear models. One linear model uses walleye (Sander vitreus) $\geq 375 \mathrm{~mm}$ in fork

792 length from the gillnet index and relates $\log _{10}$ mass to $\log _{10}$ fork length and site collected, sex, 793 gillnet mesh size, and age $\left(F=222, p<2.2 \times 10^{-16}\right.$, adjusted $\left.R^{2}=0.97\right)$. Data included in this 794 model are from the gillnet index collected by the Government of Manitoba. The other linear 795 model uses data from walleye sampled for metabolites ( $\geq 452 \mathrm{~mm}$ in fork length), and relates $796 \log _{10}$ mass to the interaction of $\log _{10}$ fork length and site collected, sex, and the interaction of $797 \log _{10}$ fork length and $\operatorname{sex}\left(F=86, p<2.2 \times 10^{-16}\right.$, adjusted $\left.R^{2}=0.94\right) . P$-values for means, 798 representing differences in intercepts are above the diagonal and $p$-values for trends, representing 799 differences in slopes are below the diagonal.

\begin{tabular}{lcccccc}
\hline & \multicolumn{3}{c}{ Gill Net Index } & \multicolumn{3}{c}{ Metabolite } \\
\hline & $\begin{array}{l}\text { Dauphin } \\
\text { River }\end{array}$ & $\begin{array}{l}\text { Matheson } \\
\text { Island }\end{array}$ & Riverton & $\begin{array}{l}\text { Dauphin } \\
\text { River }\end{array}$ & $\begin{array}{l}\text { Matheson } \\
\text { Island }\end{array}$ & $\begin{array}{l}\text { Red } \\
\text { River }\end{array}$ \\
\hline $\begin{array}{l}\text { Dauphin } \\
\text { River } \\
\text { Matheson }\end{array}$ & - & 0.60 & 0.082 & - & 0.65 & 0.081 \\
$\begin{array}{l}\text { Island } \\
\text { Riverton/ }\end{array}$ & 0.024 & - & 0.60 & 0.037 & - & 0.040 \\
Red River & 0.16 & 0.41 & - & 0.060 & 0.35 & - \\
\hline
\end{tabular}


802 Table 4. Results from a linear model relating $\log _{10}$ mass to the $\log _{10}$ fork length, basin collected, 803 study of data origin (gillnet index or metabolite), sex, the interaction of $\log _{10}$ fork length and 804 basin, and the interaction of $\log _{10}$ fork length and study $\left(F=889, p<2.2 \times 10^{-16}, R^{2}=0.97\right)$. This 805 model represents the length-mass relationship for walleye (Sander vitreus) collected for the 806 gillnet index data by the Government of Manitoba and for metabolite information by the authors. 807 These walleye were collected in 2017 , and only fish $\geq 375$ millimeters in fork length are included 808 in this model. From the gillnet index data, only walleye from the Dauphin River, Matheson 809 Island, and Riverton sites are included.

810

\begin{tabular}{lll}
\hline & $p$-value & eta squared \\
\hline $\log _{10}$ Fork Length & $<0.05$ & 0.74 \\
Basin & 0.0010 & 0.020 \\
Study & 0.98 & 0.0 \\
Sex & 0.65 & 0.0 \\
$\log _{10}$ Fork Length * Sex & 0.62 & 0.0 \\
$\log _{10}$ Fork Length * Basin & $<0.05$ & 0.019 \\
$\log _{10}$ Fork Length * Study & 0.90 & 0.0 \\
\hline
\end{tabular}

811 
813 Table 5. Results from linear models relating metabolite presence to $\log _{10}$ fork length and site

814 collected, with a separate model for each metabolite. Category represents the conceptual

815 framework used to classify the nine metabolites studied (see Figure 2 for details). Overall model

$816 p$-values are provided under their respective metabolites. $P$-values and eta squared are reported

817 for $\log _{10}$ fork length and site collected as independent variables within models. Briefly,

818 methionine, tryptophan, and lysine represent essential amino acids. Dimethyl sulfone,

819 kynurenine, and $\alpha$-aminoadipic acid represent essential amino acid breakdown. Last,

820 hydroxyproline, dimethylarginine, and methionine sulfoxide represent endogenous protein breakdown. The walleye (Sander vitreus) from which metabolites were measured for these linear models were $n=39$ individuals ( $\geq 452 \mathrm{~mm}$ in fork length) collected by boat electrofishing in 2017 from the Dauphin River, Matheson Island, and Red River representing the north basin, channel, and south basin of Lake Winnipeg, respectively. Metabolites were measured from whole blood.

826

\begin{tabular}{cllll}
\hline Category & Amino acid & $\begin{array}{l}\text { Independent } \\
\text { variable }\end{array}$ & $p$-value & eta squared \\
& Methionine & Log $_{10}$ fork length & 0.74 & 0.0020 \\
& $p=0.011$ & Site collected & 0.0070 & 0.25 \\
Essential & Tryptophan & Log $_{10}$ fork length & 0.36 & 0.019 \\
Amino Acids & $p=0.0071$ & Site collected & 0.032 & 0.17 \\
& Lysine & Log $_{10}$ fork length & 0.52 & 0.010 \\
& $p=0.020$ & Site collected & 0.046 & 0.16 \\
Amino Acid & $p=0.031$ & Log $_{10}$ fork length & 0.088 & 0.070 \\
Breakdown & Kynurenine & Site collected & 0.36 & 0.048 \\
Markers & $p=0.070$ & Log $_{10}$ fork length & 0.80 & 0.002 \\
& $\alpha$-Aminoadipic Acid & Site collected & 0.092 & 0.13 \\
& $p=0.81$ & Log $_{10}$ fork length & 0.94 & 0.0 \\
& Hydroxyproline & Site collected & 0.66 & 0.023 \\
Protein & $p=1.3 \times 10^{-18}$ & Log $_{10}$ fork length & 0.69 & 0.002 \\
Degradation & Dimethylarginine & Log $_{10}$ fork length & 0.97 & 0.60 \\
Metabolites & $p=0.0017$ & Site collected & 0.0020 & 0.0 \\
& Methionine Sulfoxide & Log $_{10}$ fork length & 0.47 & 0.30 \\
& $p=0.0016$ & Site collected & 0.0080 & 0.011 \\
& & & & 0.24 \\
\hline
\end{tabular}

\section{7}




\section{Figure Captions}

834 Figure 1. Map of Lake Winnipeg and the sites included in the present study. The Grand Rapids 835 and Dauphin River represent the north basin, Matheson Island and Frog Bay the channel, and 836 Riverton and Grand Beach the south basin, in the gillnet index data collected between 2009 and 8372018 by the Government of Manitoba. For the blood metabolite data consisting of large walleye 838 (Sander vitreus) caught by electrofishing in 2017, the Dauphin River represents the north basin, 839 Matheson Island the channel, and the Red River the south basin.

841 Figure 2. Conceptual diagram linking protein degradation and markers of amino acid breakdown 842 to walleye (Sander vitreus) growth, diet, and energy requirements. Throughout this manuscript, 843 amino acid breakdown refers to breaking down an amino acid to use it as an energy source.

844 Metabolites specific to the breakdown pathways of specific essential amino acids, indicated 845 below, were selected as markers of these processes. Meanwhile protein degradation refers to 846 proteins that are being separated back into their constituent amino acids. For the current study, 847 we used metabolites in the blood that would come specifically from post-translationally modified 848 amino acids because their release is the result or proteins that have been synthesized and 849 subsequently degraded.

Figure 3. Estimated marginal means of $\log _{10}$ fork length-at-age for walleye (Sander vitreus) from 2012 to 2018 across gillnet index collection sites in Lake Winnipeg. The data were collected by 853 the Government of Manitoba. These figures are derived from linear models relating $\log _{10}$ fork 854 length to the interaction of age with year, sex, and gillnet mesh size. A separate model was used 855 for each collection site. $95 \%$ confidence intervals are provided as error bars at each age. Overall 856 model significance and adjusted $R^{2}$ is provided in each panel. Figure 4. Estimated marginal means of log fork length-at-age between 2015 and 2018 across all sites collected for the gillnet index data in Lake Winnipeg walleye (Sander vitreus). The data

860 were collected by the Government of Manitoba. These figures are derived from linear models 861 relating log fork length to age in interaction with site, sex, and mesh size. A separate linear 862 model was used for each of the years 2015, 2016, 2017, and 2018. 95\% confidence intervals are 863 provided as error bars at each age. Overall model significance and adjusted $R^{2}$ is provided in 864 each panel.

866 Figure 5. Relative mass over time and length-mass relationships among Lake Winnipeg walleye 867 (Sander vitreus) caught in 2017. Panel A represents estimated marginal means of $\log _{10}$ mass 
between 2009 and 2018 across all sites collected for the gill net index data in Lake Winnipeg walleye (Sander vitreus). These data are pulled from a linear model relating $\log _{10}$ mass as a dependent variable to $\log _{10}$ fork length, sex, site, and mesh size as independent variables $(F=$ $2686, p<2.2 \times 10^{-16}$, adjusted $\left.R^{2}=0.98\right) .95 \%$ confidence intervals are provided as error bars at each year. For panel $B$, the linear model related $\log _{10}$ mass to the interaction of $\log _{10}$ fork length and basin collected, sex, mesh size, and age $\left(F=222, p<2.2 \times 10^{-16}\right.$, adjusted $\left.R^{2}=0.97\right)$ using the gillnet index data from the Dauphin River, Matheson Island, and Riverton sites. Panel C represents a linear model on walleye used for fish from the metabolite measurements, and this linear model related $\log _{10}$ mass in $\mathrm{kg}$ to $\log _{10}$ fork length interacting with site collected, sex, and the interaction of $\log _{10}$ fork length and $\operatorname{sex}\left(F=86, p<2.2 \times 10^{-16}\right.$, adjusted $\left.R^{2}=0.94\right)$. Panel D shows a linear model comparing length-mass relationships in walleye between those used for metabolites and from the gillnet index data. This model relates $\log _{10}$ mass as the dependent variable, with $\log _{10}$ fork length, basin collected, sex, study (metabolite or gill net index), the interaction of $\log _{10}$ fork length and basin, the interaction of $\log _{10}$ fork length and sex, and the interaction between $\log _{10}$ fork length and study as independent variables $\left(F=889, p<2.2 \times 10^{-}\right.$ adjusted $R^{2}$ is provided in each panel. The gillnet index data were collected by the Government of Manitoba and only walleye $\geq 375$ millimeters in fork length are included in this models, while in the metabolite data are large fish ( $\geq 452 \mathrm{~mm}$ in fork length) caught by electrofishing, from which whole blood metabolites were measured. $\log _{10}$ mass was calculated in kilograms, and $\log _{10}$ fork length in millimeters.

Figure 6. Estimated metabolite concentration ( $\mu \mathrm{mol}^{-1}$ in whole blood) for Lake Winnipeg walleye (Sander vitreus) by site, predicted by linear models that incorporate metabolite as the dependent variable, with $\log _{10}$ fork length and site collected as the independent variables. The three sites on the horizontal axis are the Red River (south basin), Matheson Island (channel), and Dauphin River (north basin). Here, $n=39$ large fish ( $\geq 452 \mathrm{~mm}$ in fork length) were caught by electrofishing in 2017. On the vertical axis are estimated marginal means for each metabolite. The light blue bars represent $95 \%$ confidence intervals, while the black arrows represent significance for pairwise comparisons between sites. Overall linear model significance and adjusted $R^{2}$ is provided in each panel. Panels A, B, and C represent essential amino acids. Panels $\mathrm{D}, \mathrm{E}$, and $\mathrm{F}$ represent respective amino acid breakdown metabolites that in conjunction with plots A, B, and C, may describe amino acid oxidation. Panels G, H, and I represent metabolites associated post-translational modification and therefore may reflect endogenous protein degradation (see Figure 2 for additional details). 


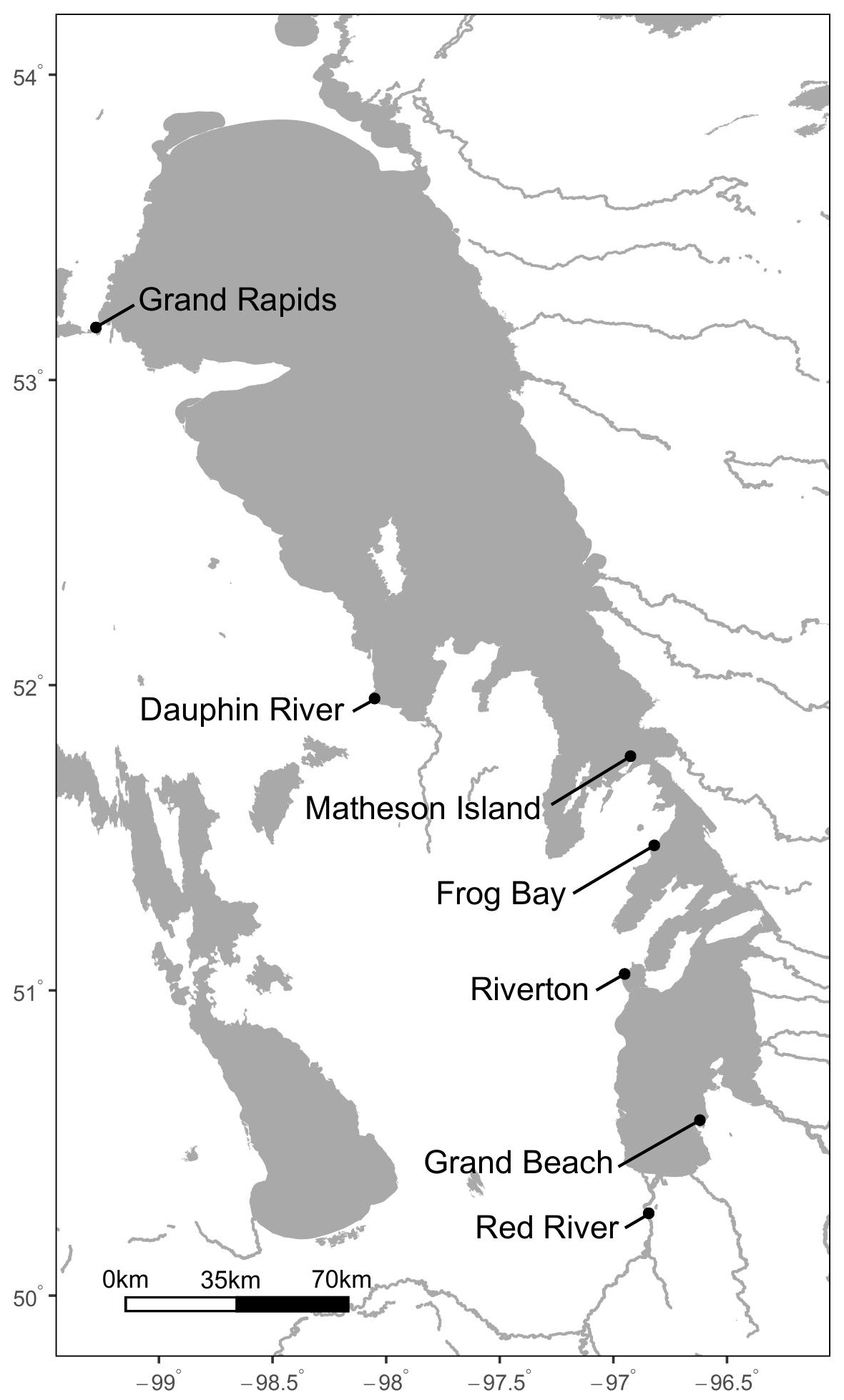




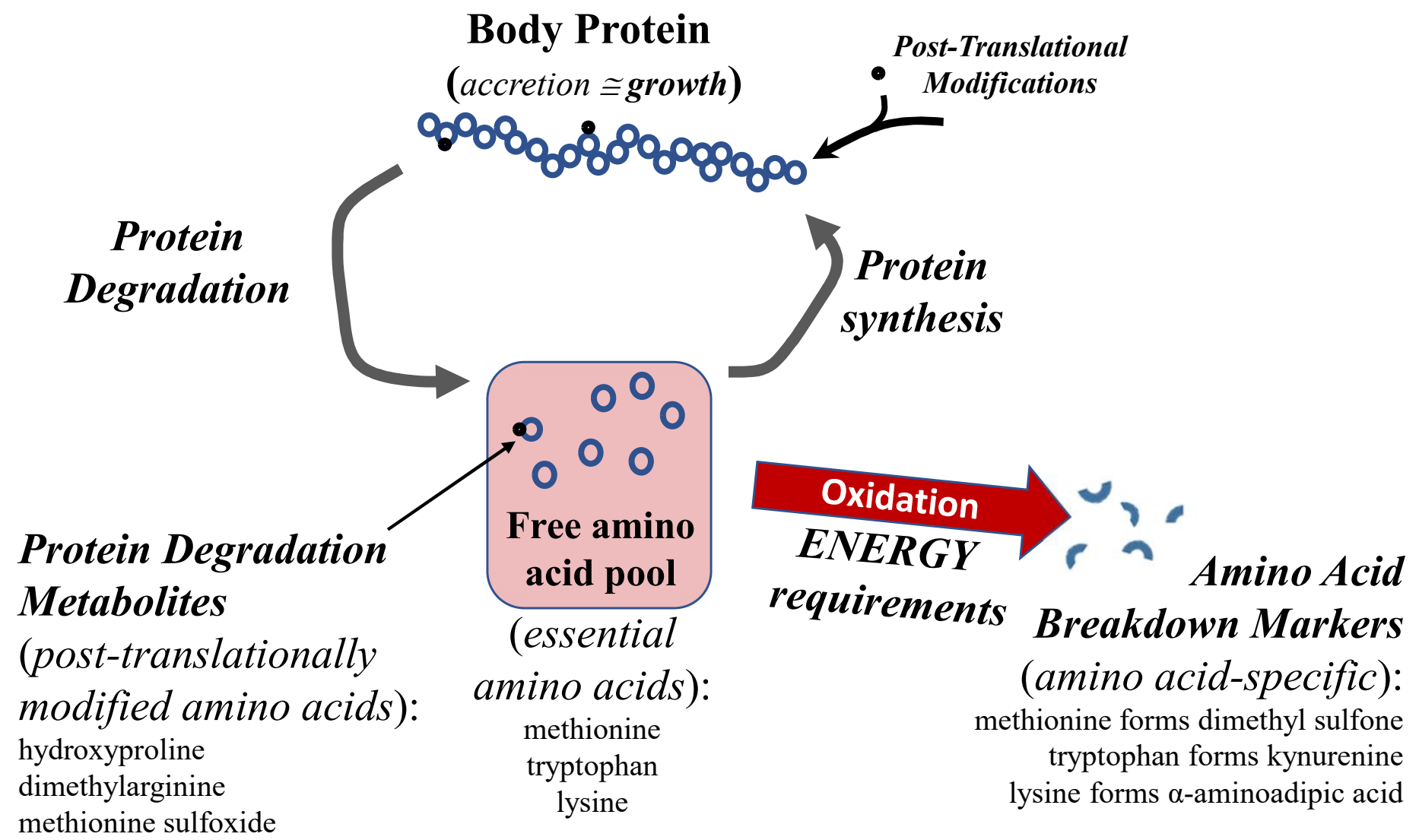




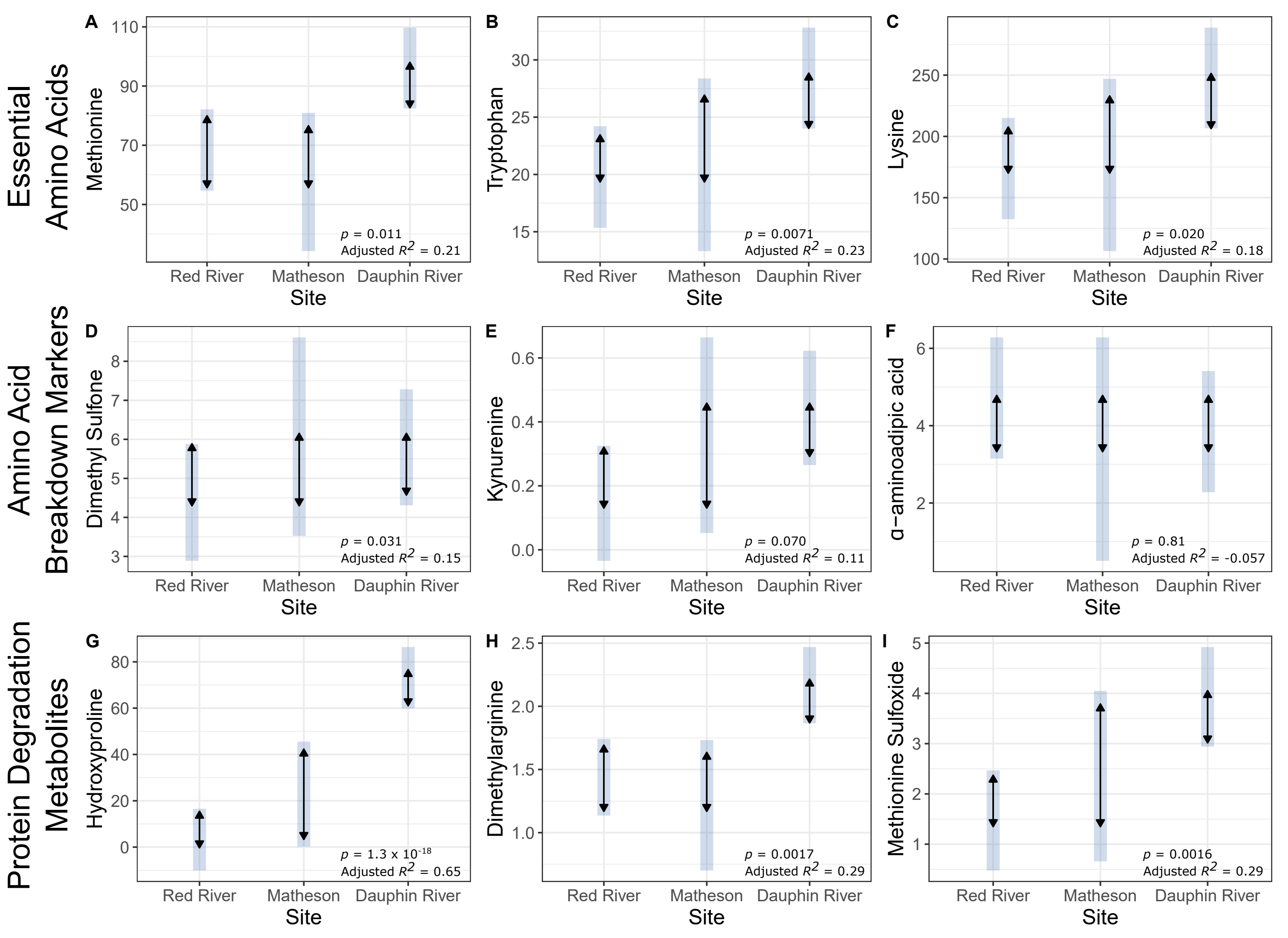

